\title{
Counterfactuals of Freedom and the Luck Objection to Libertarianism
}

Robert J. Hartman

University of Gothenburg

roberthartman122@gmail.com

Keywords: Libertarianism; Luck; Rollback Argument; Molinism; Peter van Inwagen

Abstract: Peter van Inwagen famously offers a version of the luck objection to libertarianism called the 'Rollback Argument.' It involves a thought experiment in which God repeatedly rolls time backward to provide an agent with many opportunities to act in the same circumstance. Because the agent has the kind of freedom that affords her alternative possibilities at the moment of choice, she performs different actions in some of these opportunities. The upshot is that whichever action she performs in the actual-sequence is intuitively a matter of mere chance. I explore a new response to the Rollback Argument. If there are true counterfactuals of libertarian freedom, then the agent performs the same action each time she is placed in the same circumstance, because that is what she would freely do in that circumstance. This response appears to negate the chancy intuition. Ultimately, however, I argue that this new response is unsuccessful, because there is a variant of the Rollback Argument that presents the same basic challenge to the libertarian on the assumption that there are true counterfactuals of libertarian freedom. Thus, true counterfactuals of libertarian freedom do not provide the libertarian with a solution to the Rollback Argument. 
Libertarianism is the view that free will is incompatible with causal determinism and that human beings at least sometimes act freely. Randolph Clarke (2000: 23) classifies accounts of libertarianism as 'action-centered' if the indeterminism essential to libertarian freedom is located in the production of the decision — that is, at the moment of choice. ${ }^{1}$ According to this family of views, a free agent is able at least sometimes to choose between more than one possible course of action. ${ }^{2}$ Although many philosophers believe that the ability to do otherwise at the moment of choice is a desideratum of free action or even required for free action, others think that indeterminism at the moment of choice makes whichever action occurs lucky in a way that undermines freedom.

Peter van Inwagen (2002) famously offers an intuitive version of the luck objection that has come to be known as the 'Rollback Argument.' The Rollback Argument is a thought experiment designed to show that the indeterminism essential to any kind of action-centered libertarian freedom rules out acting freely. ${ }^{3}$ Assume that Alice has some version of actioncentered libertarian freedom and that she finds herself torn in a difficult situation with strong reasons to tell the truth and strong reasons to lie (van Inwagen 2002: 171-175). Suppose that she tells the truth. Subsequently, God rolls time back to the moment $t_{1}$ that is just prior to Alice's telling the truth and allows time to move forward. What does Alice do this "second" time around? It is not the case that she must tell the truth. Given the same laws of nature and an identical past, she may perform a different action. It might be the case that she tells a lie, and it might be the case that she tells the truth again. Supposing that God rolls time back to $t_{1}$ one hundred times and in each instance allows time to resume its forward momentum, it is extremely likely that sometimes Alice tells the truth and other times she lies. After enough rollbacks, the number of times she chooses to tell the truth and to tell a lie plausibly converges on some 
definite ratio. Suppose that after the first 99 rollbacks, she tells the truth 68 times and tells a lie 32 times. And after the next 900 rollbacks, she tells the truth 699 times and tells a lie 301 times. The probability of Alice's telling the truth thus converges upon 0.7 and telling a lie upon 0.3 . These objective probabilities are conditioned on the ratio of telling the truth and telling a lie in the rollbacks.

After watching Alice make her first 726 decisions in the same token circumstance, van Inwagen (2002: 172) contends that we should be left with the "inescapable impression" that what Alice does in the $727^{\text {th }}$ rollback is a mere matter of chance - in this case a 70/30 chance. ${ }^{4}$ And there is no reason to resist this intuition, because all of Alice's character, beliefs, and desires are held fixed up until the moment of choice. The only thing that differs in a rollback in which Alice tells the truth and a rollback in which she tells a lie is her bare exertion of will. Nothing about the agent herself explains why she performs one action rather than another. But if it is true that Alice's action in the $727^{\text {th }}$ rollback is a mere matter of chance, the same is true of her choice in the actual-sequence. And since an act's occurring as a mere matter of chance rules out its being free, Alice does not act freely in the actual-sequence. The more general conclusion is that no action-centered libertarian act can be a free act, because the indeterminism that generates the freedom-undermining chanciness is common to every exercise of action-centered libertarian agency. $^{5}$

I explore a new response to the Rollback Argument. If a philosophical commitment of the Molinist view of divine providence is correct—namely, if there are true counterfactuals of libertarian freedom - then Alice performs the same action each time she is placed in the same circumstance. ${ }^{6}$ This response undermines the part of the thought experiment in which the agent chooses differently in the same circumstance. Thus, one might think that if there are true 
counterfactuals of libertarian freedom, the Rollback Argument fails to show that the indeterminism essential to action-centered libertarian acts makes them too chancy to be free. ${ }^{7}$ But a consideration from Dean Zimmerman's $(2009 ; 2011)$ anti-Molinist argument suggests that things are not so simple. By appealing to some of Zimmerman's insights, we can construct an analogous thought experiment that presents the same basic challenge to the libertarian as the original Rollback Argument on the assumption there are true counterfactuals of libertarian freedom. As a result, true counterfactuals of libertarian freedom do not ultimately provide the libertarian with a solution to the Rollback Argument's basic challenge.

I proceed as follows. In the first section, I briefly state the standard response to the Rollback Argument and explain why it is dialectically desirable to look for a different kind of response. In the second section, I offer the Molinist Response that if there are true counterfactuals of libertarian freedom, then it is not the case that Alice tells the truth in some of the rollbacks but not in others, and thus there appears to be no reason to think that Alice's action is chancy and unfree. In the third section, I explicate a variant of the Rollback Argument inspired by Zimmerman's work and argue that the libertarian still faces the same potential problem even if there are true counterfactuals of libertarian freedom.

\section{THE STANDARD RESPONSE}

Proponents of the Standard Response to the Rollback Argument accept van Inwagen's claims that are constitutive of the thought experiment, including the claim that if Alice's action is indeterministic and if God repeatedly rolls time back, it is extremely likely that she would tell the truth in some of the rollbacks and would tell a lie in others. Proponents of the Standard Response, however, deny van Inwagen's intuitive reaction to the thought experiment. In other 
words, they deny his claim that Alice's choosing differently in the rollbacks makes her actualsequence act chancy in a way that is inimical to acting freely.

Some versions of the Standard Response appeal to agent causation to explain why Alice's act is not too chancy to be free. For example, Randolph Clarke (2003: 166-167; 2005), Meghan Griffith (2005), and Timothy O’Connor and Jonathan D. Jacobs (2013: 189-190) all assert that Alice's being the agent cause of her act rules out the claim that her act is too chancy to be free, because she is the source of her act in a way appropriate to have freedom-level control over it. ${ }^{8}$ As O’Connor puts it:

The agent causationist contends that ... [the Rollback Argument fails] to take seriously the concept of agent causation. ... Alice's causing her intention to tell the truth is itself an exercise of control. And because, ex hypothesi, it is literally the agent herself generating the outcome, it is hard to see how the posited form of control could possibly be improved upon. So wherein lies the luck? (2011: 324)

Other philosophers such as Michael Almeida and Mark Bernstein (2011: 487-490), Laura Ekstrom (2011: 374-377), John Martin Fischer (2012: 95-104), and Christopher Evan Franklin (2011: 215-219; 2012: 408-409) also contend that Alice's action is not too chancy to be free but do so without appealing to agent causation.

The dialectical problem with the Standard Response is that the debate bottoms out in conflicting intuitions about whether Alice's action is chancy in a way that undermines freedom. After all, the Standard Response does not imply that there is a problem with the thought experiment; it implies only that van Inwagen's intuitive reaction to the thought experiment is offtarget. To avoid this dialectical stalemate, it is profitable to pursue responses to the Rollback Argument that move beyond this conflict of intuitions. In the next section, I explore the Molinist 
Response to the Rollback Argument, because it is the kind of response that challenges a claim that is partially constitutive of the thought experiment. ${ }^{9}$

\section{THE MOLINIST RESPONSE}

Molinism is a view of divine providence named after the sixteenth-century Spanish Jesuit Luis de Molina, and it describes God as having a strong kind of control over the action-centered libertarian free acts of his creatures. A distinctive feature of Molinism and the heart of the Molinist Response to the Rollback Argument is that there are eternally true counterfactuals of libertarian freedom. ${ }^{10}$ A counterfactual of libertarian freedom is a proposition of the following form: if agent $\mathrm{S}$ were in a complete circumstance $c, \mathrm{~S}$ would freely (in the action-centered libertarian sense) $x$. With knowledge of what any person would freely do in any particular circumstance, God is able to actualize a possible world in which agents find themselves in circumstances that guarantee that they make particular free choices. God, thus, has significant control over the free actions of his creatures. Nevertheless, he does not have total control over their free actions, because the counterfactuals of creaturely libertarian freedom that are true are so independently of his will.

Because it is entirely outside of God's control which counterfactuals of creaturely libertarian freedom are true, the true counterfactuals delimit which possible worlds he can actualize. For each possible world that God can actualize containing creatures who sometimes act freely, there is a set of propositions that aptly describe each event in that world and those propositions must be consistent with the true counterfactuals of creaturely libertarian freedom. After all, it is absurd to claim that God can actualize a world in which the set of propositions that 
describe that world's events are inconsistent with the true counterfactuals of libertarian freedom. For example, consider the following counterfactual:

P: If Phil were in complete circumstance $c$, Phil would freely drink coffee.

Assume that $\mathrm{P}$ is true. In that case, it is absurd to claim that God can actualize a possible world in which Phil freely refrains from drinking coffee in $c$, because he would freely drink coffee in $c$. Following Thomas Flint (1998: 51-54), we may call the possible worlds that the true counterfactuals permit God to actualize feasible worlds and the possible worlds that the true counterfactuals preclude God from actualizing infeasible worlds. ${ }^{11}$ It is important to see that infeasible worlds are still genuinely possible worlds. For P is merely contingently true. That is, $\sim P$ could have been true. And if $\sim P$ were true, then God would have been able to actualize a world in which Phil is in $c$ and freely refrains from drinking coffee. God's knowledge of true counterfactuals of libertarian freedom, thus, grants him significant but not total control over the free actions of his creatures.

We may now state the Molinist Response to the Rollback Argument. According to Molinism, there is a true counterfactual of libertarian freedom about what every possible agent would freely do in every circumstance in which it is possible for the agent to be. ${ }^{12}$ It follows that there is a true counterfactual about what Alice would freely do in the difficult situation (supposing for convenience that there are only two possible actions). It is either TRUTH or LIE:

TRUTH: If Alice were in the difficult situation at $\mathrm{t}_{1}$, she would freely tell the truth. LIE: If Alice were in the difficult situation at $\mathrm{t}_{1}$, she would freely tell a lie.

Assume that TRUTH is true. When Alice finds herself in the difficult situation, she tells the truth. ${ }^{13}$ And in the next rollback, she tells the truth again. In fact, in each instance of God's 
rolling time back to the difficult situation, the antecedent of TRUTH is satisfied and Alice tells the truth. Thus, Alice's telling the truth has a conditional probability of 1.0 , and this objective probability is conditioned on TRUTH. ${ }^{14}$ But because Alice's telling the truth has a conditional probability of 1.0, no one should be left with the intuition that her telling the truth is a mere matter of chance. ${ }^{15}$ That is, if we were to watch Alice tell the truth 726 times in a row, no one should have the intuition that what she does in her next rollback will be a mere matter of chance. So, the Molinist Response appears to rule out the chancy intuition, because it implies the denial of van Inwagen's claim that if Alice's action is indeterministic and if God repeatedly rolls time back, she would tell the truth in some of the rollbacks and would tell a lie in others. This response generalizes. For all actual persons, actual circumstances, and rollbacks, each person freely duplicates their "original" free decision. Therefore, if there are true counterfactuals of libertarian freedom, it appears that the Rollback Argument fails to show that action-centered libertarian acts are chancy in a way that is contrary to acting freely. ${ }^{16}$

Nevertheless, the Molinist Response will be successful only if there is no variant of the Rollback Argument that presents the same basic challenge to the libertarian on the assumption that there are true counterfactuals of libertarian freedom. In the next section, I argue that there is such a thought experiment by appealing to some of Zimmerman's work on the antecedents of counterfactuals of libertarian freedom.

\section{WHY THE MOLINIST RESPONSE FAILS}

The antecedent of a counterfactual of libertarian freedom describes an agent's being in a complete circumstance - that is, a maximally specific circumstance that includes the entire history of the world (Flint 1998: 46). As such, any small difference in remote history suffices to 
individuate a new token complete circumstance. Zimmerman (2009: 67) recognizes that there are many true counterfactuals of libertarian freedom that describe an agent in the same type of complete circumstance, and these type-identical complete circumstances differ in only remotely historical and causally irrelevant ways. So, there are lots of token complete circumstances that are exactly similar for all practical purposes to Alice's actual difficult situation but differ only by, for example, an angel's singing prior to creation or a swerve of dust prior to the Big Bang (Zimmerman 2009: 60-61). Here are three groups of counterfactuals with type-identical but token-distinct complete circumstances:

TRUTH: If Alice were in the difficult situation at $\mathrm{t}_{1}$, she would freely tell the truth. LIE: If Alice were in the difficult situation at $\mathrm{t}_{1}$, she would freely lie.

TRUTH*: If Alice were in the difficult situation* at $\mathrm{t}_{1}$, which differs from the difficult situation by only an angel's singing prior to creation, she would freely tell the truth. LIE*: If Alice were in the difficult situation* at $t_{1}$, which differs from the difficult situation by only an angel's singing prior to creation, she would freely lie.

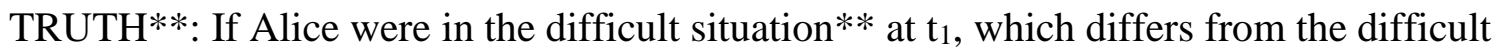
situation by only a swerve of dust prior to the Big Bang, she would freely tell the truth. LIE**: If Alice were in the difficult situation** at $\mathrm{t}_{1}$, which differs from the difficult situation by only a swerve of dust prior to the Big Bang, she would freely lie.

It is possible that TRUTH, TRUTH*, and LIE** are all true (and so possible that LIE, LIE*, and TRUTH** are all false), because the truth-value of each counterfactual of freedom with a different token complete circumstance is logically independent from all the others. Thus, it is not the case that TRUTH's being true necessitates that TRUTH*, TRUTH**, TRUTH***, and so on are also true. But if it is the case that both TRUTH and LIE** are true, then God can ensure that Alice either tells the truth or tells a lie in that type of circumstance by actualizing a possible world in which either the difficult situation or the difficult situation** obtains. So, if the true counterfactuals turn out in this way for all possible persons and for every possible type of 
complete circumstance, each possible person will be what Zimmerman (2009: 67) calls

"transworldly manipulable," because God can ensure what action each person performs for every type of complete circumstance. ${ }^{17}$

In light of Alice's possible transworldly manipulability, we may consider a new thought experiment that presents the same basic challenge to the libertarian as the original Rollback Argument. Suppose that TRUTH is true and that we watch Alice tell the truth in the difficult situation. Subsequently, "we can imagine being presented with an array of monitors that present dramatic (yet accurate) representations of the outcome of Alice's identical process of deliberation in different possible worlds" (Franklin 2012: 407). For our purposes, the only possible worlds relevant to being displayed on the monitors are feasible worlds in which Alice is in type-identical complete circumstances. For in those worlds only is Alice in circumstances that are indistinguishable from her actual difficult situation, and in those worlds only does Alice's action correspond to what she would in fact freely do.

As we watch the monitors, what would we see? Possibly, we see Alice telling the truth in some of the monitors and telling a lie in others, because the truth-values of counterfactuals of libertarian freedom with token-distinct complete circumstances are logically independent of one another. As a result, true counterfactuals of libertarian freedom do not guarantee that Alice tells the truth in each monitor. In fact, given that TRUTH is true, it seems overwhelmingly likely that at least one of the counterfactuals $\mathrm{LIE}^{*}, \mathrm{LIE}^{* *}, \mathrm{LIE}^{* * *}$, or LIE**** and so on is also true, because Alice is torn between truth-telling and lying in the difficult situation; and these other complete circumstances are indistinguishable from her actual circumstance (cf. Swinburne 2013: 206). So, it is very plausible that we see Alice tell the truth and then observe Alice tell a lie in at least some of the monitors. But then, after watching Alice sometimes telling the truth and 
sometimes telling a lie, we plausibly will be left with whatever intuition we are left with in the original Rollback Argument. ${ }^{18}$

Whether this new thought experiment succeeds in showing that true counterfactuals of libertarian freedom provide the libertarian with no answer to the Rollback Argument depends on how similar it is to the original thought experiment. I contend that the similarities are striking. In the original thought experiment, it is the case that Alice would probably tell the truth and would probably tell a lie in the same token complete circumstance, and, in the new thought experiment, it is probably the case that Alice would freely tell the truth and that Alice would freely tell a lie in type-identical but token-distinct complete circumstances. ${ }^{19}$ In other words, both thought experiments illustrate what would probably happen if Alice was repeatedly given opportunities to act in indistinguishable circumstances.

But one might object that there is a relevant difference between these thought experiments. One might object that we get a stronger chancy intuition in the original thought experiment than in the new thought experiment, because Alice is acting in the same token complete circumstance rather than in merely type-identical complete circumstances. But this assertion seems implausible. After all, the type-identical complete circumstances are objectively and phenomenologically indistinguishable from Alice's actual difficult situation in every way relevant to her performing one action or another. They differ in only historically remote and causally irrelevant ways. Thus, the mere fact that the new thought experiment has Alice in merely type-identical circumstances for each rollback and the original thought experiment has Alice repeatedly in the same token circumstance is not a relevant difference. 


\section{CONCLUSION}

I began by arguing that the Standard Response to the Rollback Argument is dialectically

undesirable, because it does not dispute a feature of the thought experiment but merely rejects

the chancy intuition. Next, I argued that one might think that the Molinist Response is a more

dialectically advantageous response, because it disputes van Inwagen's claim that if Alice's

action is indeterministic and God repeatedly rolls time back, she would tell the truth in some of

the rollbacks and would tell a lie in others. And since that claim's being true is essential for

generating the chancy intuition, it appears that the Molinist Response undermines the Rollback

Argument. Finally, I argued that we can devise a new thought experiment using Zimmerman's

insights that issues the same basic challenge to the libertarian as the original Rollback Argument

on the assumption that there are true counterfactuals of libertarian freedom. Therefore, true

counterfactuals of libertarian freedom do not ultimately provide the libertarian with an answer to

the Rollback Argument. ${ }^{20}$

\footnotetext{
${ }^{1}$ Non-action-centered accounts of libertarianism locate the indeterminism somewhere further upstream from the choice such as during deliberation. See Mele 2006: 105-135; Stump 2003: 277-306.

${ }^{2}$ The qualifier 'at least sometimes' makes room for action-centered accounts of libertarianism such as Robert Kane's (1996) in which some but not all free actions are indeterministic.

${ }^{3}$ Van Inwagen (2002: 168) assumes that Alice has agent causal power, because his ultimate aim is to falsify the widespread assumption that agent causal accounts of action-centered libertarianism $d o$ circumvent the luck objection but event causal accounts of action-centered libertarianism do not. That is, he aims to show that the luck objection to libertarianism is as problematic for agent causal varieties of libertarianism as it is for event causal varieties. Even so, the Rollback Argument may be viewed as an argument that no version of action-centered libertarianism is compatible with freedom. See Buchak 2013: 21.

${ }^{4}$ Franklin (2012: 407) also construes the thought experiment as Alice being in the same token circumstance for each rollback. But one might think that Alice finds herself in merely type-identical future circumstances. There is good reason, I think, not to characterize the thought experiment in that way. Alice plausibly cannot find herself in a type-identical future circumstance, because her telling the truth in the original circumstance has two effects on her. Her action ennobles her character, and it furnishes her with knowledge about what it is like to tell the truth in that circumstance and what consequences follow. See Kane 1996: 179-181, 145-156. Thus, Alice's dispositional states and informational input will not be the same when God constructs a new future circumstance. To avoid this problem, one might suppose that a rollback amounts to the annihilation of the world and its future re-creation to mirror the moment at which Alice is in the difficult circumstance. If God annihilates and re-creates the world in the first rollback, then Alice would be what Michael McKenna (2004: 180) calls an "instant agent," that is, an agent who begins her existence in adulthood with intellect, character, and beliefs that exactly mirror the annihilated agent. On this characterization of the thought experiment, however, it is not obvious that Alice is the same person in each
} 
rollback. See van Inwagen 1978: 118-119. And since the luck objection is not supposed to depend on the falsity of a prominent view of personal identity, this formulation is unduly contentious.

${ }^{5}$ Van Inwagen (2002: 175) believes that there is something wrong with this argument, but it is not clear to him what the mistake is.

${ }^{6}$ Counterfactuals of freedom are perhaps more aptly named 'subjunctive conditionals of freedom,' because counterfactuals of freedom with antecedents that obtain in the actual world are not contrary-to-fact. I retain the conventional mode of reference.

${ }^{7}$ I do not evaluate the claim that there are true counterfactuals of libertarian freedom. I do, however, note a few issues along the way. For thorough and opinionated introductions to these issues, see Hasker 2011; Flint 2011; Perszyk 2013.

${ }^{8}$ Clarke is no longer a proponent of agent causal libertarianism.

${ }^{9}$ Some other responses to the Rollback Argument also evade this conflict of intuitions. For example, Franklin (2012: 406-407) argues that because the Rollback Argument is metaphysically impossible, any chancy intuition that it elicits is invalid. Additionally, both Richard Swinburne (2013: 206-208) and Lara Buchak (2013: 24) dispute van Inwagen's claim that the ratio of Alice's telling the truth and telling a lie eventually converges on a definite value. And because this convergence is essential for eliciting the chancy intuition, Alice's act does not even appear to be a mere matter of chance.

${ }^{10}$ The fact that counterfactuals of freedom are true prior to the birth of the agent that they describe raises several problems for Molinism including the Grounding Objection. Roughly, the Grounding Objection is that Molinist counterfactuals must be true without being grounded in the concrete world but no proposition can be groundlessly true (Adams 1977). Interestingly, the Grounding Objection has some affinity to the luck objection to libertarianism itself. Because TRUTH is true of Alice in a groundless way, one might think that it is a matter of luck whether it is TRUTH or LIE that is true of her. In fact, Neal Tognazzini (2015) formulates a version of the luck objection to libertarianism based on the ungrounded nature of libertarian acts themselves.

${ }^{11}$ God himself is subject to circumstantial moral luck if there are true counterfactuals of libertarian freedom, because it is a matter of luck for him which possible worlds he can actualize. See Hartman 2014: 85.

${ }^{12}$ The law of the conditional excluded middle, which is often accepted by Molinists, states that for any counterfactual of freedom, either it or its logical complement is true (Flint 1998: 48-50; Fredosso 1988: 50).

${ }^{13}$ For an interesting discussion about the relationship between why a counterfactual of libertarian freedom is true and why the libertarian free act that it describes occurs, see Alexander Pruss and Joshua Rasmussen 2014.

${ }^{14}$ One might doubt that Alice's action is genuinely indeterministic on account of its conditional probability of 1.0 based on TRUTH. The laws of nature, however, do not rule out an indeterministic event with a propensity to produce more than one outcome from being repeated many times and yet always producing the same outcome. Furthermore, Alice's telling the truth and telling a lie each has a conditional probability of less than 1.0 based on features of the agent in a circumstance, because her reasons, desires, and habits in that circumstance nondeterministically incline her to bring about each possible action. So, Alice's telling the truth has a conditional probability of 1.0 based on TRUTH and has a conditional probability of less than 1.0 based on features of her in that circumstance.

${ }^{15}$ According to the Molinist, Alice had the ability to lie in the difficult circumstance. And if she were to have told a lie, the counterfactual LIE would have been true of her. So, it is up to Alice to do something such that had she done it, a different counterfactual of freedom would have been true of her (Flint 2011: 43). Nevertheless, several philosophers maintain that true counterfactuals of libertarian freedom are in tension with libertarianism itself or with motivations for libertarianism (Adams 1977; Cohen 2015; Cohen 2016; Hasker 1999; Perszyk 2003). For Molinist responses to some of these arguments, see Flint 1998: 138-178; Wierenga 2011: 131-135.

${ }^{16}$ One might think that Alice is not in the same token complete circumstance in each rollback, because any small difference in history suffices to individuate a new token complete circumstance and the number of times God reverts the world changes in each rollback. So, one might think that Alice finds herself in a token-distinct but typeidentical complete circumstance in her first rollback and every subsequent rollback. Nevertheless, this objection goes wrong by focusing on the metaphysics of the impossible - namely, God's changing the past. The Rollback Argument does not attempt to represent a way in which the world could be, but is merely a heuristic to help us grasp the nature of action-centered libertarian agency. In particular, the heuristic describes three features of actioncentered libertarian agency: the indeterminism essential to free agency precludes there from being a single action that an agent would freely do in a particular circumstance; the agent would probably perform different actions if per impossibile she were to be given many opportunities to act in the same circumstance; and nothing about the agent explains why she acts one way rather than another (van Inwagen 2002: 172; van Inwagen 1997: 227). The Molinist Response undermines the heuristic by denying the first claim. As a result, the original heuristic does not properly 
describe action-centered libertarianism, which implies that the heuristic is defective. And if we revise the heuristic in light of the Molinist account of action-centered libertarian agency, Alice always tells the truth, and the revised thought experiment does not elicit the chancy impression.

${ }^{17}$ Here is a summary of Zimmerman's anti-Molinist argument. Zimmerman $(2009 ; 2011)$ argues that a certain kind of combination of true counterfactuals of libertarian freedom about a person rules out her being a free agent. It is helpful to divide the argument into two stages. First, Zimmerman (2009: 48-75) argues that it is possible that the true counterfactuals of libertarian freedom about a person turn out such that the agent would freely perform different kinds of actions in type-identical but token-distinct complete circumstances. This claim generalizes to all possible persons. Second, Zimmerman (2009: 75-84) argues that if the true counterfactuals turn out that way, then God can manipulate which of several kinds of actions any person performs in any type of complete circumstance, and this kind of global divine control is intuitively incompatible with being a free agent. For our purposes, only the first part is relevant. Molinists tend to accept the first part and focus their criticism on the second. See Craig 2011: 158-161; Wierenga 2011: 136-138.

${ }^{18}$ If it is integral to the Rollback Argument that the ratio of telling the truth and telling a lie converges on a definite value, then we can add to the thought experiment a similar convergence for the counterfactuals of freedom with type-identical antecedents as we consider more of them.

${ }^{19}$ In the original thought experiment, the form of the counterfactual is 'If S were in complete circumstance $c, \mathrm{~S}$ would probably freely $x$,' and, in the revised thought experiment, the form of the counterfactual is 'It is probably the case that if $\mathrm{S}$ were in complete circumstance $c, \mathrm{~S}$ would freely $x$.' For a discussion of these kinds of counterfactuals, see Hartman 2017: 75-78.

${ }^{20}$ I thank Joel Archer, Yishai Cohen, Thomas Flint, John Greco, Jonathan Jacobs, Gideon Jeffrey, Josh Johnson, Andrew Kissel, Joshua Rasmussen, Michael Rota, Dan Sheffler, Eleonore Stump, Harrison Waldo, and Dean Zimmerman for comments and conversations about the central idea of this essay. Additionally, I am very grateful to two referees from this journal for excellent comments that greatly improved this paper. Finally, I thank audiences at the Central Division of the American Philosophical Association, Midwest Meeting of the Society for Christian Philosophers, and Midsouth Philosophy Conference.

\section{BIBLIOGRAPHY}

Adams, Robert Merrihew. 1977. "Middle Knowledge and the Problem of Evil.” American Philosophical Quarterly 14: 109-117.

Almeida, Michael and Mark Bernstein. 2011. "Rollbacks, Endorsements, and Indeterminism.” In The Oxford Handbook of Free Will, 2 edition. ed. Robert Kane. Oxford: Oxford University Press, 484-495.

Buchak, Lara. 2013. "Free Acts and Chance: Why the Rollback Argument Fails." The Philosophical Quarterly 63: 20-28.

Clarke, Randolph. 2000. “Modest Libertarianism.” Philosophical Perspectives 14: 21-45. 2003. Libertarian Accounts of Free Will. Oxford: Oxford University Press. 2005. "Agent Causation and the Problem of Luck." Pacific Philosophical Quarterly 86: 408-421.

Cohen, Yishai. 2015. "Molinists (Still) Cannot Endorse the Consequence Argument." International Journal of Philosophy of Religion 77: 231-246.

2016. “Counterfactuals of Divine Freedom." International Journal of Philosophy of Religion 79: 85-105. 
Craig, William Lane. 2011. “Another Failed Anti-Molinist Argument.” In Molinism: The Contemporary Debate. ed. Ken Perszyk. Oxford: Oxford University Press, 144-162.

Ekstrom, Laura. 2011. "Free Will Is Not a Mystery." In The Oxford Handbook of Free Will, 2 edition. ed. Robert Kane. Oxford: Oxford University Press, 366-380.

Fischer, John Martin. 2012. "Indeterminism and Control: An Approach to the Problem of Luck." In Deep Control: Essays on Free Will and Value. ed. John Martin Fischer. Oxford, Oxford University Press, 85-105.

Flint, Thomas P. 1998. Divine Providence: The Molinist Account. Ithaca: Cornell University Press.

2011. "Whence and Wither the Molinist Debate: A Reply to Hasker." In Molinism: The Contemporary Debate. ed. Ken Perszyk. Oxford: Oxford University Press, 37-49.

Franklin, Christopher Evan. 2011. "Farewell to the Luck (and Mind) Argument." Philosophical Studies 156: 199-230.

2012. "The Assimilation Argument and the Rollback Argument." Pacific Philosophical Quarterly 93: 395-416.

Fredosso, Alfred J. 1988. "Introduction." In On Divine Foreknowledge: Part IV of the "Concordia". ed. Alfred Fredosso. Ithaca: Cornell University Press, 1-81.

Griffith, Meghan Elizabeth. 2005. "Does Free Will Remain a Mystery: A Response to van Inwagen." Philosophical Studies 124: 261-269.

Hartman, Robert J. 2014. "How to Apply Molinism to the Theological Problem of Moral Luck." Faith and Philosophy 31: 68-90.

2017. In Defense of Moral Luck: Why Luck Often Affects Praiseworthiness and Blameworthiness. New York: Routledge.

Hasker, William. 1999. “A New Anti-Molinist Argument.” Religious Studies 35: 291-297.

2011. "The (Non-)Existence of Molinist Counterfactuals." In Molinism: The Contemporary Debate. ed. Ken Perszyk. Oxford: Oxford University Press, 25-36.

Kane, Robert. 1996. The Significance of Free Will. Oxford: Oxford University Press.

McKenna, Michael. 2004. "Responsibility and Globally Manipulated Agents." Philosophical Topics 32: 169-192.

Mele, Alfred. 2006. Free Will and Luck. Oxford: Oxford University Press.

O'Connor, Timothy. 2011. "Agent Causal Theories of Freedom." In The Oxford Handbook of Free Will, 2 edition. ed. Robert Kane. Oxford: Oxford University Press, 309-328. 
O'Connor, Timothy and Jonathan D. Jacobs. 2013. "Agent Causation in a Neo-Aristotelian Metaphysics." In Mental Causation and Ontology. ed. E. J. Lowe. Oxford: Oxford University Press, 173-192.

Perszyk, Kenneth J. 2003. "Molinism and the Consequence Argument: A Challenge." Faith and Philosophy 20: 131-151. 2013. "Recent Work on Molinism." Philosophy Compass 8: 755-770.

Pruss, Alexander R. and Joshua L. Rasmussen. 2014. "Explaining Counterfactuals of Freedom." Religious Studies 50: 193-198.

Stump, Eleonore. 2003. Aquinas. New York: Routledge.

Swinburne, Richard. 2013. Mind, Brain, and Free Will. Oxford: Oxford University Press.

Tognazzini, Neal A. 2015. “Grounding the Luck Objection.” Australasian Journal of Philosophy 93: $127-138$.

van Inwagen, Peter. 1978. “The Possibility of Resurrection.” International Journal for Philosophy of Religion 9: 114-121. 1997. “Against Middle Knowledge." Midwest Studies in Philosophy 21: 225-236. 2002. "Free Will Remains a Mystery." In The Oxford Handbook of Free Will. ed. Robert Kane. Oxford: Oxford University Press, 158-177.

Wierenga, Edward. 2011. “Tilting at Molinism.” In Molinism: The Contemporary Debate. ed. Ken Perszyk. Oxford: Oxford University Press, 118-139.

Zimmerman, Dean. 2009. "Yet Another Anti-Molinist Argument." In Metaphysics and the Good: Themes from the Philosophy of Robert Merrihew Adams. eds. Samuel Newlands and Larry M. Jorgensen. Oxford: Oxford University Press, 33-94. 2011. “An Anti-Molinist Replies.” In Molinism: The Contemporary Debate. ed. Ken Perszyk. Oxford: Oxford University Press, 163-186. 